\title{
Ação sindical, contestação política e siderurgia na Amazônia brasileira
}

\section{Trade union action, contentious politics and steel industry in the Brazilian Amazon}

José Ricardo Ramalho - Professor titular de Sociologia do Programa de Pós-Graduação em Sociologia e Antropologia da Universidade Federal do Rio Janeiro (UFRJ)/Brasil-Rio de Janeiro-Rio de Janeiro. E-mail: jricardoramalho@uol.com.br

Marcelo Sampaio Carneiro - Professor associado da Universidade Federal do Maranhão (UFMA)/ Brasil-Maranhão-São Luís. E-mail: marcelosc@uol.com.br

\section{Resumo}

A proposta do texto é discutir as estratégias de contestação social desenvolvidas a partir da reação de movimentos sociais aos impactos da crise econômica de 2008 sobre a produção siderúrgica na Amazônia, tomando como referência a análise desse processo no município de Açailândia (MA). Ao abordar essa situação de conflito social, o texto descreve os repertórios de ação coletiva utilizados pelos metalúrgicos e seus aliados, através da constituição de uma aliança entre diferentes grupos sociais que se sentiram prejudicados pelos desdobramentos da crise econômica. Os resultados obtidos por essa mobilização mostram, em determinados contextos, a possibilidade de atores coletivos atuarem e modificarem relações de poder no âmbito de uma Rede de Produção Global.

\begin{abstract}
The purpose of the text is to discuss strategies of contentious politics that were created as a reaction of social movements to the consequences of the 2008 economic crisis on the industrial production of pig iron in the Amazon, especially in the municipality of Açailândia, in the state of Maranhão. In order to describe this situation of social conflict, the text goes through the repertories of collective action used by metalworkers and their allies, and the construction of an alliance of different social groups that were affected by the crisis. The results of this kind of mobilization indicate that, in some contexts, it is possible for collective actors to change power relations in the scope of a global production network.
\end{abstract}

\section{Palavras-chave}

Ação Coletiva. Sindicalismo. Siderurgia. Rede de Produção Global.

\section{Keywords}

Collective Action. Trade Unionism. Steel Production. Global Production Network. 


\section{INTRODUÇÃO}

Projetos de desenvolvimento de grande repercussão econômica, política e social, ao serem implantados em diferentes localidades, trazem consigo uma dinâmica de transformações com impactos variados sobre a sociedade e o território. $\mathrm{O}$ processo de adaptação às novas relações sociais criadas por essas intervenções tem desdobramentos complexos, com percepções e práticas que variam do apoio e da defesa das iniciativas, pela criação de mais empregos e de mais atividades econômicas; até sua contestação em razão dos seus efeitos, como a precarização das relações de trabalho, a degradação do meio ambiente, e o desrespeito aos direitos humanos.

Na última metade do século XX, a Amazônia brasileira presenciou a emergência de diferentes tipos de reação a estes projetos, opondo movimentos sociais aos seus principais implementadores - agentes estatais e empresas privadas (cf. CASTRO, 1989; HÉBETTE, 1991; ACEVEDO MARIN; CASTRO, 1993; ANDRADE; SOUZA FILHO, 2006). Investigar a manifestação dessas práticas de resistência e descrever as trajetórias dos principais atores, permite aprofundar o debate sobre a construção de formas de contestação política a processos de desenvolvimento.

A proposta desse texto é identificar os repertórios acionados para reivindicar e criticar as desigualdades criadas por esses projetos tomando como base os impactos do Programa Grande Carajás sobre Açailândia (MA), uma das principais cidades do corredor ferroviário estabelecido pela construção da Estrada de Ferro Carajás, e que foi escolhida para abrigar um aglomerado industrial composto por empresas produtoras de ferro gusa. A ênfase se dará sobre o contexto da mais recente crise do capitalismo mundial em 2008, e pelo fato dessas empresas serem elos de uma Rede de Produção Global (RPG) (HENDERSON et al., 2011), dedicadas à exportação.

A retração na atividade econômica norte-americana, provocada pela "crise das hipotecas subprime" (HARVEY, 2011), afetou diretamente a produção de ferro gusa na Amazônia oriental. O resultado imediato foi o corte de postos de trabalho, o rebaixamento salarial e a redução das atividades produtivas, mesmo nas firmas que tinham acumulado lucros nos anos anteriores (cf. CARNEIRO; RAMALHO, 2009).

Potencializadas por esse novo contexto, as reações locais às estratégias empresariais não só se ampliaram como forjaram ou reforçaram alianças de diferentes atores sociais (incluindo até mesmo o empresariado local e os diferentes níveis da administração pública) que identificaram prejuízos, injustiças 
e desrespeito aos direitos básicos dos trabalhadores, culminando com uma greve de trabalhadores metalúrgicos em 2011.

\section{CRISE ECONÔMICA E CONFRONTO POLÍTICO NALOCALIDADE}

As situações de conflito criadas em Açailândia, a partir da crise de 2008, apontam para novos exemplos de articulação política e de utilização de recursos sociais como forma de tornar mais efetivas as reivindicações dos grupos insatisfeitos. A busca de elementos explicativos para os processos de mobilização e de confronto, nesse caso, ajuda a compreender os diferentes estágios por que passam as forças políticas de resistência de modo a criar constrangimentos e demandar mudanças por parte das empresas, dos órgãos públicos e dos grupos dominantes locais.

A greve operária e o confronto político dela derivada serão tomados como exemplo para refletir teoricamente sobre a constituição de movimentos que podem questionar os resultados de políticas de desenvolvimento regional. A ênfase na dinâmica local, a partir de contextos de experiência industrial, se explica como modo de identificar se há ou não instâncias criadas com o objetivo de construir acordos justificados (BOLTANSKI, 1990) que sejam capazes de atender as demandas de setores desfavorecidos ou atingidos negativamente pelas práticas empresariais.

Será possível dizer que no contexto de crise econômica, quando a crítica às empresas evoluiu para um confronto político, houve acúmulos no movimento social de resistência? O evento político que servirá de exemplo para a reflexão foi um conflito de classe, uma greve operária, que se enquadra no repertório tradicional dos conflitos entre capital e trabalho (TILLY; TARROW, 2007, 2008). Mas nesse caso, os trabalhadores lançaram mão de outros tipos de apoio, pouco comuns nessa esfera de reivindicações e pressão social, através da articulação com movimentos sociais locais voltados para o enfrentamento da questão ambiental e urbana, produzindo um repertório novo de ações coletivas diante de ameaças trazidas pela instabilidade econômica. Mesmo que a ênfase seja nos operários, um setor social com pautas e repertórios de ação já tradicionais, a experiência local contribuiu para identificar o estabelecimento de novos laços sociais, durante o processo de mobilização.

O processo de implantação do polo siderúrgico de Açailândia, ao introduzir novos atores (empresas siderúrgicas, trabalhadores metalúrgicos, trabalhadores florestais), abriu também uma chance para a formulação de reivindicações até 
então ausentes do contexto regional. Contudo, de forma semelhante ao que ocorreu com outras propostas de desenvolvimento para a Amazônia, baseadas na grande empresa agropecuária (COSTA, 2000), ou na exploração mineral (MONTEIRO, 2003), a estratégia de implantação de polos industriais esteve mais preocupada com a eficácia da acumulação do que com as demandas locais relativas ao trabalho ou ao meio ambiente, ainda que fosse justificada pela (boa) ideia da promoção da desconcentração industrial e, por conseguinte, da incorporação local de benefícios esperados - em termos de emprego e renda pelo estabelecimento de um polo siderúrgico regional (CARNEIRO, 1989).

A leitura dos eventos pós-crise em Açailândia dialoga com diferentes abordagens teóricas, dentre as quais a da análise sobre o confronto político ${ }^{1}$ é uma referência importante. De acordo com Tilly e Tarrow (2007; 2008), o confronto ocorre a partir de repertórios de mobilização que são utilizados pelos movimentos sociais para atingirem seus objetivos. Contudo, esses repertórios não nascem do nada, pois, "geralmente, aqueles que empunham a bandeira de uma reivindicação coletiva inventam suas ações no interior de limites fixados por um repertório preexistente para o lugar, o tempo e a relação sujeito-objeto da reivindicação em questão" (TILLY; TARROW, 2008, p. 40). No contexto social em análise, o repertório de mobilização utilizado pelo movimento operário (audiências públicas, ocupação de vias públicas) foi elaborado a partir do contato com ações desenvolvidas por outros movimentos sociais (de camponeses e de direitos humanos).

Vale destacar também, que no conflito em questão, os trabalhadores metalúrgicos tiveram de confrontar diferentes atores sociais (as empresas siderúrgicas, uma grande empresa mineradora e o Estado brasileiro), atuando em uma arena política ${ }^{2}$ que não tinha como alvo um único oponente. Nesse sentido, podemos dizer que a contestação aqui analisada se desenvolveu em diferentes

\footnotetext{
1 Tilly e Tarrow (2007, p. 4-9) consideram que "políticas de contestação põem junto três características familiares da vida social: disputa, ação coletiva e política". "Quando disputa, política e ação coletiva se juntam, alguma coisa distinta acontece: poder, interesses compartilhados, e políticas governamentais entram em cena. Reivindicações se tornam coletivas, o que significa que dependem de alguma forma de coordenação entre as pessoas que estão fazendo as reivindicações. Também se tornam políticas, ao menos assumindo a presença dos governos como monitores, garantidores, ou reguladores da reclamação coletiva e frequentemente mais diretamente como sujeitos ou objetos das reclamações."

2 Utilizamos o conceito de arena política no sentido indicado pela socioantropologia do desenvolvimento, pois, de acordo com Olivier de Sardan (2005, p. 185-189), "em uma arena, grupos estratégicos heterogêneos se confrontam, levados por interesses mais ou menos compatíveis (materiais ou simbólicos), os atores possuindo níveis ou influências de poder maiores ou menores". Neveu (2000, p. 16-17) desenvolve argumento similar, analisando a atuação de movimentos sociais através da constituição de "arenas de conflitos sociais".
}

Novos Cadernos NAEA • v. 16 n. $1 \cdot$ p. 7-28 • jun. 2013 
espaços institucionais, deslocando, de acordo com o alvo da mobilização, o foco da reivindicação para empresas e/ou o Estado, sem conferir primazia a qualquer desses atores (MATHIEU, 2002; ANCELOVICI; ROUSSEAU; 2009).

A avaliação dos eventos de Açailândia, a partir da perspectiva do conflito, traz também elementos para um debate sobre a questão da inserção de empresas e territórios em redes de produção global (RPG) e a disputa pelo valor que circula nessas redes (cf. HENDERSON et al., 2011; SANTOS, 2011). As empresas produtoras de ferro gusa estão vinculadas à montante da Cia. Vale do Rio Doce (Vale), através da compra de minério de ferro e, à jusante com empresas (tradings, aciarias etc.) que comercializam e/ou beneficiam o ferro gusa, transformando-o em aço ou derivados de aço, constituindo uma RPG específica, cujo produto final (aço) é vendido para montadoras de automóveis (Ford, GM, BMW, Mercedes e Nissan) nos Estados Unidos (cf. GREENPEACE, 2012). A interpretação em termos de RPG possui a vantagem de complexificar o debate, permitindo a apreciação do poder de outros atores, que antes passava despercebido, caso das empresas siderúrgicas locais (poder corporativo), da ação estatal em suas diferentes esferas (poder institucional) e dos sindicatos, associações de moradores e organizações não governamentais (poder coletivo) (HENDERSON et al., 2011). No caso da RPG do ferro gusa na Amazônia, a capacidade de interferência dos atores locais pode ser empiricamente verificada através da ação dos movimentos de direitos humanos pela erradicação do trabalho escravo na cadeia de fornecimento de carvão vegetal para as siderúrgicas (CARNEIRO, 2008; PITOMBEIRA, 2011) ou na iniciativa das empresas para obter autonomia face ao monopólio da venda de minério de ferro pela Vale, através do investimento para obtenção de minério de ferro em minas próprias.

\section{O POLO SIDERÚRGICO DE CARAJÁS E A CRISE ECONÔMICA DE 2008}

Um breve resumo da história da implantação e evolução dos polos siderúrgicos do Programa Grande Carajás demonstra que desde o início essa ação de desenvolvimento foi objeto de críticas por causa de seus impactos sociais e ambientais. A existência de trabalho escravo na cadeia produtiva da siderurgia a carvão vegetal colocou em cheque a legitimidade do processo produtivo, permitindo o crescimento dos movimentos de contestação ao modelo de desenvolvimento implementado ${ }^{3}$.

A crítica se dirige principalmente aos efeitos sociais e ambientais provocados pela introdução 
Até o final de 1980, a produção de ferro gusa a carvão vegetal estava concentrada no estado de Minas Gerais e somente na década seguinte é que houve um deslocamento regional importante, com o surgimento das primeiras unidades fabris na Amazônia oriental, localizadas nos municípios de Açailândia (MA) e Marabá (PA). Essa reorientação da produção siderúrgica está relacionada aos incentivos (isenção fiscal e subsídios) oferecidos pelo governo federal no âmbito do Programa Grande Carajás e da construção, por parte da Cia. Vale do Rio Doce, de infraestrutura para escoamento do minério de ferro de Carajás, através de uma moderna ferrovia e do porto de Ponta da Madeira em São Luis (MA) (CARNEIRO, 1989).

A produção siderúrgica deu seus primeiros passos na Amazônia no final dos anos 1980, mas, foi somente no início desse século que ela ganhou musculatura, chegando, em 2006, a responder por 1/3 do total do ferro gusa produzido com carvão vegetal no Brasil. Deve-se ressaltar que essa expansão está ligada à elevação do preço do ferro gusa, que passou de US\$110,00/t em 2002 para US $\$ 510,00 / \mathrm{t}$ em $2008^{4}$, e em alguns contratos atingiu o valor de US\$880,00, segundo informação de um representante da empresa Sidenorte. E também ao fato de que a exigência de um volume relativamente pequeno de recursos para a implantação de uma unidade de produção de ferro gusa favoreceu a entrada de novos produtores - mesmo sem experiência anterior - nesse campo econômico.

Após mais de uma década de crescimento contínuo (1994 a 2007), o Polo Siderúrgico de Carajás (PSC) sofreu com a crise de 2008 principalmente pela dependência que tem da economia norte-americana. Se a crise econômica afetou o setor siderúrgico pelo lado dos consumidores finais, a decisão tomada pela empresa Vale, em 2010, de aumentar o preço do minério de ferro de Carajás de US $\$ 48,00$ para US\$ $137,00^{5}$, pressionou os custos dessas empresas pelo lado dos fornecedores de insumo, afetando suas margens de lucro ${ }^{6}$.

da siderurgia na Amazônia Oriental, caso da existência de trabalho escravo na cadeira de fornecimento de carvão vegetal para as siderúrgicas e da contribuição que essa produção de carvão adicionou ao processo de desmatamento de florestas tropicais na região (CARNEIRO, 2008; ASSIS; CARNEIRO, 2012).

4 Cf. informação do Radar Comercial, ferramenta de monitoramento das exportações brasileiras, disponível na homepage do Ministério do Desenvolvimento Indústria e Comércio (MDIC).

5 Segundo informação do Presidente do STIMA, Jarlis Adelino. De acordo com a jornalista Vera Saavedra Durão a elevação do preço teria sido menor, passando de US\$ 37,00 para US\$ 80,00 (Fabricantes de ferro-gusa esperam reajuste de até 150\%, Valor Econômico, 12-14/03/2010, B-6).

6 Outro componente a ser considerado é a taxa de câmbio. A apreciação do real frente ao dólar tornou as exportações brasileiras menos competitivas frente aos principais produtores na Ucrânia e na Rússia.

Novos Cadernos NAEA • v. 16 n. $1 \cdot$ p. 7-28 • jun. 2013 
A figura1 mostra a evolução recente (2000 a 2011) do valor das exportações de ferro gusa realizadas pelas siderúrgicas do Maranhão e do Pará. Percebe-se nitidamente os efeitos da crise sobre a produção guseira, que depois de atingir seu mais alto valor em 2008, com a exportação de 1,581 bilhão de dólares, reduziu este valor para 613 milhões em 2010. Vale destacar, no entanto, que já no ano de 2011 as exportações apresentaram um sinal de recuperação, crescendo para o valor de 975 milhões dólares.

Gráfico 1: Evolução do valor das exportações do PSC (em mil dólares FOB)

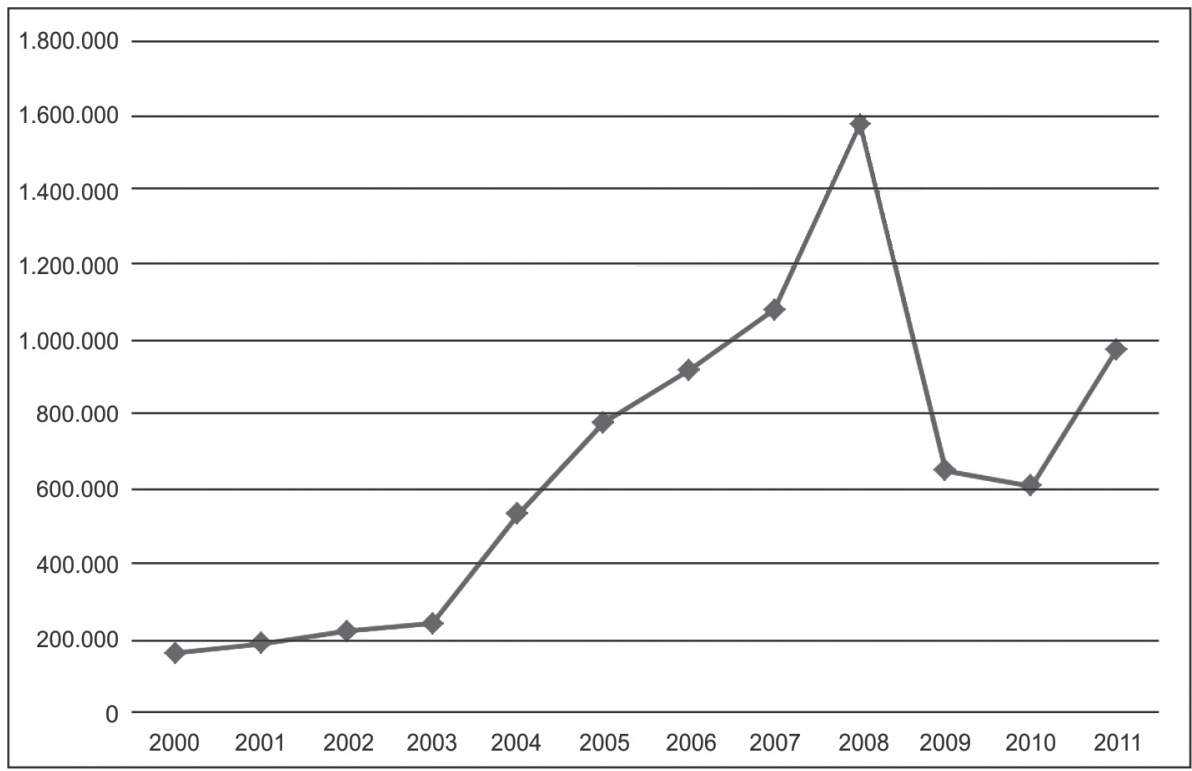

Fonte: Secretaria de Comércio Exterior (MDIC)

Em 2009, o diretor da Associação Comercial Industrial de Marabá (ACIM), Ítalo Ipojucam ${ }^{7}$, destacou que das dez empresas localizadas em Marabá (PA), cinco estavam com a produção totalmente parada, enquanto as demais com exceção da Sidepar - haviam reduzido suas atividades. Para as empresas localizadas no estado do Maranhão o cenário era semelhante, conforme relatou o presidente do Sindicato das Indústrias de Ferro Gusa do Maranhão (SIFEMA): "das sete empresas deste segmento, apenas três - Viena, Gusa Nordeste e Vale do Pindaré [...] - estão operando e com apenas 20 por cento da capacidade, enquanto as demais - Margusa (Bacabeira), Cosima (Pindaré-Mirim), Fergumar

7 Entrevista com Ítalo Ipojucam - Associação Comercial Industrial de Marabá (ACIM), 22.01.2009. 
(Açailândia) e Simasa (Açailândia) - simplesmente desativaram os fornos, depois da retração dos compradores internacionais"».

O fechamento total ou parcial das empresas traduziu-se na demissão de milhares de trabalhadores e na redução de direitos para os operários metalúrgicos que continuavam empregados. No caso do município de Açailândia (MA), a onda de demissões e de subtração de direitos ganhou repercussão nacional:

Cerca de 40\% dos 3.000 metalúrgicos de Açailândia (MA) foram demitidos desde outubro de 2008 como reflexo da crise econômica mundial, segundo o sindicato da categoria. A principal atividade econômica da cidade é a produção de ferro-gusa para exportação, cuja demanda mundial sentiu fortemente o impacto da crise (Cidade do Maranhão registra corte de 40\% dos metalúrgicos, Folha Online, 28.02.2009).

\section{A CRONOLOGIA DO CONFLITO POLÍtico: ATORES E EVENTOS NO PROCESSO DE MOBILIZAÇÃO}

A demissão em massa desencadeou uma série de mobilizações por parte dos movimentos sociais locais. Estes, ao mesmo tempo em que denunciavam a atitude das empresas - que se anteciparam aos efeitos da crise demitindo trabalhadores já no início de 2008 - também colocaram em debate o modelo de desenvolvimento centrado na exploração intensiva do trabalho e de recursos naturais (minério de ferro e recursos florestais), e orientado para o mercado externo. Trechos de uma carta que sintetizou os resultados da primeira audiência pública para discutir os efeitos da crise econômica em Açailândia demonstra uma posição crítica ao modelo de desenvolvimento vigente.

Pautadas no fato de que os grandes empreendimentos econômicos na região têm ao longo dos anos causado sérios problemas ambientais em função do desmatamento, pecuária extensiva, sojicultura, cultivo do eucalipto entre outros, as entidades da sociedade civil pontuaram no evento a importância de mudar as formas de desenvolvimento econômico, priorizando a implantação de projetos de recuperação das florestas com espécies nativas, a fixação dos trabalhadores rurais no campo, por meio de incentivos fiscais de órgãos financeiros estatais. Pediram também que os órgãos de governo discutam de maneira participativa os projetos que pretendem implantar na região (Carta do Movimento Popular em Favor da Justiça e da Dignidade Humana, Açailândia, 21.05.2009).

Nesse processo, além da situação dos trabalhadores metalúrgicos, ganhou destaque a reivindicação da Associação de Moradores do Bairro do

8 Claudio Azevedo é empossado na Asibras, O Imparcial, 03.06.2009, p. 7.

Novos Cadernos NAEA • v. 16 n. $1 \cdot$ p. 7-28 • jun. 2013 
Pequiá - antigo povoado camponês, escolhido nos anos 1980 para sediar o Polo Siderúrgico de Açailândia (CANCELA, 1992) -, que exigia a construção de um novo assentamento urbano para abrigar as famílias que sofrem cotidianamente com os efeitos da poluição do ar resultante das atividades fabris. Esta luta se notabilizou pela divulgação do relatório "Quanto valem os direitos humanos?”, produzido pelas ONG Federação Internacional dos Direitos Humanos (FIDH), Justiça Global e pela Campanha Justiça nos Trilhos ${ }^{9}$. Ou seja, o contexto de crise possibilitou a confluência de críticas que vinham sendo desenvolvidas separadamente por trabalhadores metalúrgicos, através de demandas de uma maior participação nos resultados financeiros obtidos pelas empresas nos anos pré-crise; e pelo movimento de defesa dos direitos humanos, voltado para as consequências ambientais e sociais oriundas da implantação da siderurgia a carvão vegetal ${ }^{10}$.

Embora os efeitos da crise econômica sobre a indústria de ferro gusa só tenham se manifestado em 2009, as empresas, já no segundo semestre de 2008, começaram a demitir trabalhadores. Segundo relato de diretores do Sindicato dos Trabalhadores da Indústria Metalúrgica de Açailândia (STIMA) e de informações do Cadastro Geral de Empregados e Desempregados do Ministério do Trabalho e Emprego, houve um total de 1.033 demissões em Açailândia, das quais 312 na indústria de transformação. Nesse primeiro momento, a direção do STIMA não conseguiu realizar nenhuma atividade pública de resistência.

Em maio de 2009, liderados pela Igreja Católica local, um conjunto de entidades lança o "Movimento Popular em favor da Justiça e da Dignidade Humana". Este movimento promove uma audiência pública para discutir os impactos da crise sobre a vida dos metalúrgicos e chamar a atenção não só para as demissões como para outras perdas trabalhistas como a redução dos salários e da jornada de trabalho (de 8 horas para 6 horas diárias), a supressão de valores adicionais conquistados (adicional noturno, hora-extra etc.), a retirada da cesta básica mensal e da alimentação (café, almoço e jantar) fornecida pelos refeitórios das empresas. Além da situação dos trabalhadores, essa primeira audiência também colocou em discussão e tornou públicas as fragilidades da economia do município de Açailândia, derivada de sua grande dependência de um produto de

9 O relatório encontra-se disponível no endereço: http://global.org.br/programas/quantovalem-os-direitos-humanos- $\%$ E2\% $\% 0 \% 93$-os-impactos-sobre-os-direitos-humanos-daindustria-da-mineiracao-e-da-siderurgia-em-acailandia/

10 Com destaque para as denúncias sobre as ocorrências de situações de trabalho escravo na cadeia de fornecimento de carvão vegetal para as empresas siderúrgicas (CARNEIRO, 2008; GREENPEACE, 2012). 
exportação (ferro gusa) fortemente suscetível às oscilações da economia global ${ }^{11}$, particularmente do comportamento do mercado norte-americano (SANTOS 2010).

Essa situação começou a mudar com a eleição, em outubro de 2009, de uma nova diretoria para o STIMA. Composta por membros mais jovens e vinculados com a principal central sindical brasileira, a Central Única dos Trabalhadores (CUT), a nova diretoria não só reorganizou o sindicato com uma intensa campanha de filiação e de recuperação financeira, como começou a articular ações conjuntas com outros movimentos sociais no plano local.

Em 2010, surgiu uma oportunidade política (TILLY; TARROW, 2008) para o sindicato dos metalúrgicos desenvolver ações contra o desemprego e aumentar o seu poder de pressão. No mês de março, a empresa Vale, detentora do monopólio de fornecimento de minério de ferro para as siderúrgicas locais ${ }^{12}$, anunciou a elevação do preço do produto de US\$ 48,00 para US\$137,00; o que levou essas empresas, através do seu sindicato - Sindicato das Indústrias de Ferro Gusa do Estado do Maranhão (SIFEMA) - a se aproximaram do órgão de representação dos trabalhadores sugerindo uma ação conjunta de pressão contra a decisão da principal fornecedora.

O fato da empresa Vale ter sido a principal responsável pela implantação dos polos siderúrgicos na Amazônia oriental (CARNEIRO, 1989; MONTEIRO, 1998) e por ser considerada mantenedora da siderurgia na região, ao fornecer minério de ferro e administrar o transporte ferroviário que possibilita a exportação do ferro gusa, fez dela o foco central da crítica dos diferentes movimentos sociais (camponês, direitos humanos, sindical etc.) e dos questionamentos quanto ao modelo de desenvolvimento vigente na região. Por essa razão, ao reagir contra a elevação do preço do minério de ferro ${ }^{13}$, em coincidência com as empresas siderúrgicas, o sindicato dos metalúrgicos usou de forma positiva para os seus

11 A produção de ferro gusa implica também em um conjunto de atividades urbanas auxiliares (transporte, montagem e reparo dos altos-fornos) e atividades rurais (reflorestamento para produção de carvão vegetal). Essa última atividade possui um grande impacto na geração de postos de trabalho, o que potencializou os efeitos da crise na siderurgia sobre o mercado de trabalho.

12 A empresa Siderúrgica do Pará S/A, sediada em Marabá (PA), é a única empresa do campo da produção siderúrgica de Carajás que possui uma jazida própria de minério de ferro. A partir do episódio da elevação do preço do minério de ferro pela Vale, outras empresas passaram a investir na aquisição de jazidas próprias.

13 Segundo pesquisa realizada em 2004, o minério de ferro respondia por $1 / 4$ do custo de produção de ferro-gusa na Amazônia, valor inferior apenas ao do carvão vegetal (MONTEIRO, 2006, p. 77). Para a produção de uma tonelada de ferro gusa são necessárias 1,6 toneladas de minério de ferro.

Novos Cadernos NAEA • v. 16 n. 1 • p. 7-28 • jun. 2013 
interesses de reivindicação a oportunidade de se associar a um conjunto tão diversificado de atores sociais.

O sindicato dos metalúrgicos de Açailândia (STIMA) [...] protesta e se manifesta junto aos trabalhadores contra os aumentos abusivos no preço vendido da tonelada de minério de ferro extraído de Carajás no Estado do Pará, e fornecido às indústrias maranhenses pela multinacional VALE, colocando assim vários postos de trabalho em risco real de sua extinção total, além de promover perda de divisas para o Estado [...]. A COMPANHIA VALE nos anos 80 estimulou a instalação dessas indústrias no estado especialmente em Açailândia, porque não havia para quem vender seu minério de ferro. Hoje a COMPANHIA VALE simplesmente ignora o setor, o ferro gusa produzido pelas siderúrgicas tem $50 \%$ do seu custo vinculado ao preço do minério de ferro, somente no primeiro semestre deste ano, a VALE aumentou o preço do minério de ferro em mais de 171\%, de US $\$ 48$ para mais de US\$130. Essa alta cria um absoluto desequilíbrio para as Indústrias de Ferro Gusa e representa uma grande injustiça com as Indústrias Siderúrgicas Maranhense e seus trabalhadores que estão perdendo seus empregos (Metalúrgicos de Açailândia divulgam manifesto contra práticas da Vale, Portal dos Metalúrgicos do Brasil, 12.07.2010).

Nesse processo de mobilização contra a Vale, em 12 de julho de 2010, o STIMA realizou uma reunião com o presidente do Senado e ex-presidente da República, José Sarney, que declarou seu compromisso com a busca de uma solução para a crise do setor siderúrgico ${ }^{14}$. No mês seguinte, os metalúrgicos solicitaram a realização de uma audiência pública na Assembleia Legislativa do Estado do Maranhão (ALEMA) para debater a situação de Açailândia. Nesse contexto, se apropriaram politicamente de uma bandeira levantada pela "Campanha Justiça nos Trilhos" "15, passando a designar seu movimento como “Assim não VALE”. O relato abaixo revela a eficácia da mobilização:

Uma comitiva de 41 representantes de entidades, metalúrgicos do polo guseiro e representantes de sindicatos e associações que apoiam o movimento ASSIM NÃO VALE, esteve presente na Assembleia Legislativa do Estado do Maranhão, em reunião com os deputados [...]. Na oportunidade, (os deputados) confirmaram compromisso de realizar um esforço concentrado para intermediar a sobrevivência das guseiras açailandenses ameaçadas de fechar, depois que a multinacional Vale aumentou em mais de $171 \%$ o preço cobrado pela tonelada do minério de ferro (Jornal dos Metalúrgicos, Edição no 03/2010, p. 2).

14 Jornal dos Metalúrgicos, n. 02/2010, p. 1.

15 Cf. informações da campanha em sua página na internet: http://www.justicanostrilhos.org/ quem-somos 
Em agosto de 2010, o STIMA, junto com outros movimentos sociais, realizou outra audiência pública em Açailândia. Convocada em nome das entidades que compõem o "Movimento Popular em Favor da Justiça e da Dignidade Humana", essa audiência discutiu os efeitos da crise econômica e seus impactos no município e na região, sugerindo ações para o soerguimento da economia regional, através do apoio a luta dos trabalhadores metalúrgicos e de outras iniciativas econômicas. A matéria publicada no Jornal dos Metalúrgicos descreve a audiência e a expectativa gerada pela atuação conjunta dos movimentos sociais:

Ao todo são 19 entidades unidas e encabeçada pelo Sindicato dos Metalúrgicos de Açailândia, que tem a bandeira contrária aos aumentos abusivos no preço do minério de ferro praticado pela multinacional Vale, que levou a demissão de mais de quatro mil pais de famílias do município e está levando o Polo Siderúrgico do distrito industrial do Pequiá à falência. A audiência foi acompanhada de perto pelos trabalhadores, que continuam em atividade e pelos trabalhadores demitidos pela crise. Também contou com a presença da comunidade. O evento trouxe mais de 300 pessoas ao auditório e durante o evento, o presidente do sindicato pronunciou que a entidade pleiteia no Ministério do Trabalho e Emprego, em Brasília, a extensão de mais três parcelas do seguro desemprego para os trabalhadores do Polo, demitidos durante a crise no setor (Vale: metalúrgicos de Açailândia realizam audiência pública, Portal dos Metalúrgicos do Brasil, 02.09.2010).

Na sequência da mobilização, em 23 de novembro de 2010, realizou-se a audiência pública na Assembleia Legislativa do Estado do Maranhão, com foco nas demissões de trabalhadores do Polo Industrial de Açailandia. A audiência foi coordenada por cinco comissões da Assembleia (Defesa dos Direitos Humanos; Meio Ambiente, Minas e Energia; Economia, Indústria, Comércio e Turismo; Previdência, Assistência Social e da Família e Relações do Trabalho e Administração Pública), em atendimento à solicitação dos trabalhadores. A realização desta audiência também teve impacto na imprensa estadual, sendo noticiada pelos principais veículos de comunicação, além de ter conseguido mobilizar o apoio dos parlamentares para a defesa do emprego e da indústria siderúrgica. Durante o evento, o presidente do STIMA anunciou que a pressão sobre a Vale tinha produzido resultados e que a empresa iria reduzir o preço da tonelada de minério de ferro de US\$137,00 para US\$93,00, o que foi confirmado pelo presidente do sindicato das indústrias - SIFEMA ${ }^{16}$.

O sucesso do movimento pela redução do preço do minério de ferro e a retomada do crescimento das exportações de ferro gusa (figura 1) permitiu ao STIMA iniciar o ano de 2011 com uma pauta mais forte de reivindicações. Um

16 Jornal dos Metalúrgicos, n. 04/2011, p. 2.

Novos Cadernos NAEA • v. 16 n. $1 \cdot$ p. 7-28 • jun. 2013 
dos resultados concretos da reunião de forças políticas com interesses diferentes, mas voltado para objetivos associados às demandas sociais mais urgentes da comunidade, foi a organização de uma greve dos trabalhadores metalúrgicos para recompor perdas salariais e evitar novas demissões. De acordo com depoimento do presidente do sindicato:

Eu ia toda a noite por volta de uma hora da manhã, meia noite que era troca de turno, para não assustar as empresas, os empresários, para conversar com os trabalhadores à noite. Isso passou três meses, eu insistindo [...] com os trabalhadores para fazer alguma atividade para chamar a atenção dos empresários, porque eles reduziram, cortaram hora extra, cortaram a cesta básica, não dava alimentação, nem café da manhã, nem almoço, nem janta, cortaram tudo a uma escravidão mesmo e o salário muito pequeno. [...] Eu falei, companheiros nós vamos fazer uma greve aí a gente fez [...]. Se dependesse da coragem deles infelizmente não ia. Só que chegou num patamar que já não precisou mais tanto de mim. Eles mesmos viram que tinham condições de paralisar (Entrevista com Jarlis Adelino e diretoria do sindicato dos metalúrgicos de Açailândia (MA), em 16.02.2012, em Açailândia).

O principal alvo da ação sindical foi a empresa Viena Siderúrgica, a maior do Polo Siderúrgico de Açailândia, cuja paralisação teve início em 14 de fevereiro de 2011. Contudo, com o desenvolvimento do movimento, as demais empresas foram afetadas (Fergumar, Queiroz Galvão Siderurgia e Gusa Nordeste).

Desde as Oh desta segunda-feira (14.02.2011), os trabalhadores da Viena Siderúrgica, em Açailândia, estão de braços cruzados. Segundo o Sindicato dos Metalúrgicos, os trabalhadores protestam contra a falta de condições de trabalho na empresa (Viena) e também por um reajuste de $35 \%$ nos salários, para compensação da perda salarial ocorrida com a redução da jornada de trabalho, que passou de $8 \mathrm{~h}$ para $6 \mathrm{~h}$ diárias, desde agosto de 2009. "Os trabalhadores também reivindicam o retorno da cesta básica mensal, que também foi suspensa pela diretoria da empresa logo após assinatura da convenção coletiva de trabalho", disse o presidente do Sindicato, Jarlis Adelino (Trabalhadores na Viena Siderúrgica entram em greve no Maranhão, Portal dos Metalúrgicos do Brasil, 14.02.2011).

A greve começou como uma mobilização operária típica, com a ocupação e o fechamento da principal via de acesso à unidade industrial da Viena Siderúrgica, e contou com o apoio decisivo do movimento de moradores do bairro do Pequiá de Baixo.

A possibilidade de ação conjunta com o movimento popular foi percebida pela direção do STIMA como uma forma de aumentar o poder de pressão sobre as empresas. 
Vendo que lá tem uma comunidade que é o Pequiá de Baixo que estava movendo uma ação há mais de cinco anos e nunca conseguia nada na justiça, nós nos aproximamos da associação e convidamos os moradores do Pequiá. [...]. Então misturou todo mundo, misturou a comunidade, misturou os trabalhadores, misturou o sindicato, os curiosos, e a imprensa bateu em cima, [...] a polícia cruzou os braços e nos deixou a vontade. $\mathrm{E}$ aí, em menos de 48 horas, a gente conseguiu o que a gente queria $100 \%$ do pedido foi aceito (Entrevista com Jarlis Adelino e diretoria do sindicato dos metalúrgicos de Açailândia (MA), em 16.02.2012).

O resultado concreto dessa mobilização conjunta foi a disponibilização de recursos por parte do SIFEMA para a aquisição de um terreno (de 38 ha) para o reassentamento dos moradores do Pequiá de Baixo $^{17}$ e uma vitória significativa para os metalúrgicos, que tiveram a quase integralidade de suas reivindicações atendidas, como foi o caso da retomada da jornada de trabalho de 8 horas diárias, o retorno da cesta básica para todos os trabalhadores, um reajuste salarial de $8 \%$ e a garantia do não desconto dos dias parados ${ }^{18}$.

\section{GREVES, OCUPAÇÕES E AUDIÊNCIAS PÚBLICAS: OS DIFERENTES REPERTÓRIOS DO CONFLITO POLÍTICO}

Uma das características mais importantes do processo de ocupação da Amazônia brasileira tem sido o seu caráter conflitivo, quer se trate da relação entre camponeses e a grande propriedade fundiária (HEBETTE, 1991; COSTA, 2000), entre peões e a grande empresa (ESTERCI, 1987), entre a burocracia estatal e os atingidos por grandes projetos (CASTRO, 1989) e, em período mais recente, entre grupos sociais urbanos (operários, moradores de bairros) e seus antagonistas. A mobilização dos operários da indústria siderúrgica de Açailândia serve para destacar a forma como novos repertórios de mobilização coletiva vêm sendo incorporados por esses movimentos sociais, ao mesmo tempo em que demostra a possibilidade da atuação de atores sociais dominados em interferir no âmbito das disputas que envolvem redes de produção globais.

A história recente das mobilizações dos trabalhadores metalúrgicos de Açailândia (EVANGELISTA, 2008) revela um padrão de mobilização tradicional,

17 A campanha pelo reassentamento dos moradores do Pequiá de Baixo teve início em abril de 2008, quando a Associação Comunitária de Pequiá de Baixo procurou o Centro de Defesa da Vida e dos Direitos Humanos de Açailândia (CDVDH) e a Paróquia São João Batista, solicitando uma parceria para enfrentar o grave problema da poluição provocada pelas siderúrgicas no distrito industrial (BOSSI, 2010).

18 Jornal dos Metalúrgicos, n. 4/2011, p. 1.

Novos Cadernos NAEA • v. 16 n. $1 \cdot$ p. 7-28 • jun. 2013 
com o desenvolvimento de paralisações por fábrica e duas greves gerais, por ocasião da negociação dos acordos coletivos da categoria. O conflito gerado pela crise de econômica de 2008 modifica esse quadro, com a incorporação de um novo repertório de mobilizações, em que se destaca o papel desempenhado pelas audiências públicas e a aliança com outros movimentos sociais.

A utilização de audiências públicas como instrumento de mobilização pode ser compreendida como um mecanismo acionado pelos movimentos sociais de Açailândia para a elaboração de um discurso unificado frente aos diferentes problemas gerados pela crise econômica, ao mesmo tempo em que permitem a apresentação de demandas para diferentes opositores na arena política local, caso das empresas siderúrgicas, mas também de outros atores com responsabilidades nesse processo, caso da empresa Vale e das diferentes agências estatais relacionadas como o Ministério do Trabalho e Emprego, o Governo do Estado do Maranhão e a Prefeitura Municipal.

Outro aspecto que chamou a atenção no desenvolvimento dessas audiências foi sua flexibilidade quanto ao local de realização e aos objetivos a serem alcançados. Elas puderam ser realizadas no local do conflito, mas também em outros locais, como a que ocorreu na Assembleia Legislativa, em São Luís, exigindo um deslocamento das representações dos movimentos sociais. Em ambas as situações, o elemento que dá força a esse instrumento é o de possibilitar que as reivindicações apresentadas sejam formuladas para um público mais amplo $^{19}$, permitindo a adesão de novos aliados e o aumento de sua legitimidade.

A singularidade dessa mobilização também está no fato de que ela envolveu desde o início uma articulação com outros atores sociais, já enraizados nas lutas sociais de Açailândia, como é o caso da ação pastoral da Igreja Católica, do Movimento de Defesa dos Direitos Humanos e das associações de moradores.

O apoio da Igreja Católica foi decisivo para que a nova direção sindical metalúrgica passasse a ocupar o centro do conflito político ${ }^{20}$. A nova diretoria se apresentou mais qualificada e mais articulada nacionalmente, soube aproveitar o apoio local à causa dos metalúrgicos, bem como a oportunidade política (TILLY; TARROW, 2008) de fazer uma frente comum com o sindicato patronal das empresas siderúrgicas contra a decisão de aumentar o preço do minério de ferro por parte da Vale.

19 Beynon (1999, p. 11) ao descrever conflito ambiental no Reino Unido também identifica a força das audiências públicas: "nas audiências que presenciamos, ficou claro que os moradores locais que protestavam queriam que suas vozes fossem ouvidas. Nesse sentido, a audiência oferecia-lhes um foro onde podiam participar e ter sua vez de falar".

20 De forma semelhante ao narrado por Ramalho (2012) para o caso das demissões que atingiram a indústria metalúrgica na região Sul Fluminense na crise econômica de 2008. 
O fato da implantação da siderurgia na Amazônia estar associada a uma política governamental de desenvolvimento, que, em tese, deveria significar a evolução da região de uma base de exportação para a de um polo siderúrgico, com vistas a agregar valor à exploração mineral (CARNEIRO, 1989), permitiu que os problemas de uma localidade pudessem ser apresentados pelos metalúrgicos como uma questão mais ampla, de dimensão nacional, viabilizando a associação de diversos atores importantes no processo de constrangimento político sobre a empresa fornecedora de minério de ferro.

Um último aspecto a ser destacado refere-se à discussão sobre as possibilidades de disputa pelo aumento e a captura de valor por parte de trabalhadores envolvidos numa rede global de produção. A ação do sindicato dos metalúrgicos, dos movimentos sociais e das organizações não governamentais de Açailândia em contraposição a uma lógica econômica de acumulação da rede global parece indicar a capacidade e a possibilidade de interferência de um poder local nesse processo e confirma a percepção da importância do papel dos agentes não econômicos ${ }^{21}$. Da mesma forma, este caso confirma a perspectiva de que as análises sobre processos de desenvolvimento devem considerar as relações capital-trabalho como codeterminantes desses processos. Para Selwyn (2012, p. 222), os trabalhadores não podem ser vistos como vítimas passivas de um capital que busca trabalho barato. Para este autor, a forma e o conteúdo das relações capital-trabalho devem ser consideradas centrais para o processo de desenvolvimento.

\section{CONSIDERAÇÕES FINAIS}

A reunião de forças políticas entre os metalúrgicos, através do sindicato, e os moradores do Pequiá de Baixo, em luta contra os efeitos da poluição industrial, ao combinar a pauta trabalhista com a pauta ambiental, na verdade inaugurou uma prática política que tende a ser um reflexo de anos de resistência e organização contra os efeitos socialmente danosos da presença do polo siderúrgico na região. Nesse contexto, questões específicas do trabalho e do emprego se transformaram em questões mais amplas e deram o mote para a manifestação do acúmulo de força política concentrada nos últimos anos.

21 Segundo Santos (2011, p. 134-138), "ainda que a modelagem espacial do paradigma das RPGs tenda a privilegiar certos agentes (econômicos) em detrimento de outros, em função de suas imobilidades relativas, a fixidez da ação local dos agentes sociais, quando combinada a formas específicas de conversão de suas estratégia e cosmovisão em interesses coletivos, é capaz de proporcionar graus de poder bastante imprevistos a estes agentes. Em dados contextos, pode inclusive 'bloquear' a agencia de operadores econômicos no território".

Novos Cadernos NAEA • v. 16 n. $1 \cdot$ p. 7-28 • jun. 2013 
Os casos graves de descumprimento da legislação trabalhista e de atentado aos direitos humanos básicos são motivo suficiente para a contestação política e a articulação de instituições e movimentos sociais para protestar e exigir mudanças no comportamento das empresas siderúrgicas. Além da crítica de organizações nacionais (CPT, CUT, MST, entre outros) e internacionais que expõem em escala extralocal (nacional e transnacional) a reputação das empresas dessa rede produtiva global $^{22}$, torna-se cada vez mais importante investigar também as especificidades da crítica e da contestação que se constroem no espaço local. A força da articulação local, no caso analisado, ganha destaque na conjuntura da crise.

A junção das reivindicações salariais e de condições de trabalho, com a questão dos danos ambientais, e a solidariedade que se construiu a partir desse evento político, aceleraram o amadurecimento de um tipo de movimento de resistência que se manifestava de forma isolada e de certa forma colocaram em cheque estratégias de desenvolvimento industrial até então comandadas de modo unilateral.

O envolvimento do sindicato com a questão do desemprego de uma forma mais ampla levou seus dirigentes a usar estratégias bastante pragmáticas em termos de posicionamento político e de classe, como mostra o Quadro 1, juntando esforços, em alguns momentos, com as próprias empresas siderúrgicas, para combater a elevação do preço do minério de ferro e o descaso da Vale com as localidades sob sua influência.

Quadro 1: Principais etapas da contestação, segundo o alvo da mobilização e os principais opositores e aliados do movimento sindical

\begin{tabular}{|l|l|l|l|}
\hline Principal questão & Período & Principais oponentes & \multicolumn{1}{|c|}{ Principais aliados } \\
\hline $\begin{array}{l}\text { Demissões dos } \\
\text { trabalhadores }\end{array}$ & $2008 / 2009$ & $\begin{array}{l}\text { Empresas siderúrgicas } \\
\text { Estado (Ministério do } \\
\text { Trabalho e Emprego) }\end{array}$ & $\begin{array}{l}\text { Igreja Católica } \\
\text { Movimentos sociais } \\
\text { urbanos }\end{array}$ \\
\hline $\begin{array}{l}\text { Redução do preço } \\
\text { do minério de } \\
\text { ferro }\end{array}$ & 2010 & $\begin{array}{l}\text { Empresa fornecedora } \\
\text { do minério (Vale) }\end{array}$ & $\begin{array}{l}\text { Empresas siderúrgicas } \\
\text { Campanha Justiça nos } \\
\text { Trilhos } \\
\text { Lideranças políticas } \\
\text { nacionais }\end{array}$ \\
\hline $\begin{array}{l}\text { Recuperação dos } \\
\text { direitos trabalhistas }\end{array}$ & 2011 & Empresas siderúrgicas & $\begin{array}{l}\text { Movimento de bairro } \\
\text { Movimento de direitos } \\
\text { humanos } \\
\text { Igreja Católica }\end{array}$ \\
\hline
\end{tabular}

22 Phillips (2011: 164-65) argumenta que os principais resultados obtidos por campanhas de combate ao trabalho forçado em RPG, estão associados a atuação de organizações não governamentais e instituições extralocais como a Organização Internacional do Trabalho (OIT), que colocam em risco a credibilidade das marcas associadas a essas empresas. 
No momento posterior, quando vencida a luta pela redução do preço do minério de ferro e com a recuperação parcial do fluxo de importações do ferro gusa, o sindicato dos metalúrgicos usou da força moral e política acumulada na mobilização para pressionar as empresas siderúrgicas, logrando recuperar os direitos que haviam sido tirados dos trabalhadores no ápice da crise em 2008/2009.

Por fim, há que considerar estratégias e repertórios de ações utilizados pelo sindicato e pelos movimentos sociais como forma de pressionar e reivindicar por melhores condições de vida e de trabalho. Um resumo da mobilização crescente em Açailândia pode ser visto no Quadro 2.

Quadro 2: Os diferentes repertórios do conflito político em Açailândia

\begin{tabular}{|l|l|l|l|l|}
\hline & $\begin{array}{c}\text { Movimento } \\
\text { popular }\end{array}$ & \multicolumn{1}{|c|}{$\begin{array}{c}\text { Movimento } \\
\text { camponês }\end{array}$} & $\begin{array}{c}\text { Movimento } \\
\text { de direitos } \\
\text { humanos }\end{array}$ & $\begin{array}{l}\text { Movimento } \\
\text { sindical } \\
\text { urbano }\end{array}$ \\
\hline $\begin{array}{l}\text { Principais } \\
\text { organizações }\end{array}$ & $\begin{array}{l}\text { Associações de } \\
\text { moradores de } \\
\text { bairros } \\
\text { Plenária urbana } \\
\text { de Açailândia }\end{array}$ & $\begin{array}{l}\text { STTR, } \\
\text { Movimento dos } \\
\text { Trabalhadores } \\
\text { Sem Terra }\end{array}$ & $\begin{array}{l}\text { Centro de } \\
\text { Defesa da Vida } \\
\text { e dos Direitos } \\
\text { Humanos, } \\
\text { Campanha Justiça } \\
\text { nos Trilhos }\end{array}$ & STIMA \\
\hline $\begin{array}{l}\text { Período de } \\
\text { implantação }\end{array}$ & $\begin{array}{l}\text { Início dos anos } \\
\text { 1980 }\end{array}$ & $\begin{array}{l}\text { Início dos anos } \\
1980\end{array}$ & $\begin{array}{l}\text { Segunda metade } \\
\text { dos anos 1990 }\end{array}$ & $\begin{array}{l}\text { Início dos } \\
\text { anos 1990 }\end{array}$ \\
\hline $\begin{array}{l}\text { Principal } \\
\text { alvo da } \\
\text { mobilização }\end{array}$ & $\begin{array}{l}\text { Estado } \\
\text { (governo } \\
\text { municipal) } \\
\text { e empresas } \\
\text { siderúrgicas }\end{array}$ & $\begin{array}{l}\text { Proprietários } \\
\text { de terras } \\
\text { (latifundiários) }\end{array}$ & $\begin{array}{l}\text { Empresas } \\
\text { siderúrgicas, } \\
\text { fazendeiros e } \\
\text { Estado (governo } \\
\text { federal e estadual) }\end{array}$ & $\begin{array}{l}\text { Empresas } \\
\text { siderúrgicas }\end{array}$ \\
\hline $\begin{array}{l}\text { Repertório } \\
\text { de } \\
\text { mobilizações }\end{array}$ & $\begin{array}{l}\text { Manifestações } \\
\text { de rua e } \\
\text { apresentação } \\
\text { de petições. }\end{array}$ & $\begin{array}{l}\text { Ocupações } \\
\text { de terras e de } \\
\text { logradouros } \\
\text { públicos }\end{array}$ & $\begin{array}{l}\text { Audiências } \\
\text { públicas, } \\
\text { elaboração de } \\
\text { relatórios }\end{array}$ & $\begin{array}{l}\text { Greves } \\
\text { do setor e } \\
\text { paralisações } \\
\text { por empresas }\end{array}$ \\
\hline
\end{tabular}

Fonte: Carneiro (1994, 1997); Evangelista (2008); Pitombeira (2011).

O uso de instrumentos variados, a importância atribuída às audiências públicas, além de mecanismos de protesto como a greve e as manifestações de rua, revelam a constituição de um tipo local de poder político enraizado que pode começar a contestar as desigualdades da sociedade local, as estratégias de desenvolvimento implementadas autoritariamente e o predomínio da lógica dos principais agentes econômicos.

Novos Cadernos NAEA • v. 16 n. $1 \cdot$ p. 7-28 • jun. 2013 


\section{REFERÊNCIAS}

ACEVEDO MARIN, R.; CASTRO, E. Negros do Trombetas: guardiões das matas e rios. Belém: NAEA, 1993.

ANCELOVICI, M.; ROUSSEAU, S. Presentation. Les mouvements sociaux et le complexité institutionelle. Sociologie et Sociétés, v. 41, n. 2, p. 5-19, 2009.

ANDRADE, M. de P.; SOUZA FILHO, B. (Orgs.). Fome de farinha: deslocamento compulsório e insegurança alimentar em Alcântara. São Luís: EDUFMA, 2006.

ASSIS, W.S.; CARNEIRO, M.D.S. Uso del carbón vegetal como fuente de energía para el Parque Siderúrgico de Carajás: controversias ambientales, sociales y económicas. In: PORRO, R.; TONI, F. (Orgs.). Energía, medio ambiente y desarrollo en la Amazonía. Madrid: Editorial Academica Espanola, 2012. p. 245-272.

BEYNON, H. Protesto ambiental e mudança social no Reino Unido. Mana, Rio de Janeiro, v. 5, n. 1, p. 7-28, 1999.

BOLTANSKI, L. L'amour et la justice comme compétences: trois essais de sociologie de l'action. Paris: Métailié, 1990.

BOSSI, D. Impactos e resistências em Açailândia: profundo interior do Maranhão. [s.n.t.], 2010. Arquivo do Autor.

CANCELA, C. D. Estação Piquiá: um novo quilômetro na fronteira Amazônica. Revista Desenvolvimento e Cidadania, São Luís, n. 2, v. 6, p. 10-21, dez-fev. 1992/1993.

CARNEIRO, M.S. Crítica social e responsabilização empresarial. Análise das estratégias para a legitimação da produção siderúrgica na Amazônia oriental. Caderno CRH, v. 21, p. 323-336, 2008.

Do latifúndio agropecuário à empresa latifundiária carvoeira. In: COELHO, M.C.N.; COTA, R.G. (Org.). 10 anos da Estrada de Ferro Carajás. Belém: NAEA, 1997. p. 223-250.

Estado e empreendimentos guseiros no Programa Grande Carajás. In: CASTRO, E. et al. (Org.). Amazônias em tempo de transição. Belém: UFPA/ NAEA/ARNI/CELA, 1989. p. 151-192.

O Programa Grande Carajás e a dinâmica política na área de influência da Estrada de Ferro Carajás. In: CASTRO, E.; MOURA, E.; MAIA, L. (Org.). Industrialização e Grandes Projetos: desorganização e reorganização do espaço. Belém: UFPA, 1994. p. 112-138. 
; RAMALHO, J.R. A crise econômica mundial e seu impacto sobre o setor siderúrgico maranhense: relações entre o desempenho recente das empresas guseiras e o desemprego no município de Açailândia. In: CARNEIRO, M.S.; COSTA, W.C. da (Org.). A terceira margem do rio: ensaios sobre a realidade do Maranhão no novo milênio. São Luis: EDUFMA, 2009. p. 37-48.

CASTRO, E.M.R. Resistência dos atingidos pela barragem de Tucuruí e construção de identidades. In: CASTRO, E.; HÉBETE, J. (Orgs.). Na trilha dos grandes projetos. Belém: NAEA, 1989. (Cadernos do NAEA, n. 10)

COSTA, F. de A. A formação agropecuária da Amazônia: os desafios do desenvolvimento sustentável. Belém: NAEA, 2000.

ESTERCI, N. Conflito no Araguaia: peões e posseiros contra a grande empresa. Petrópolis: Vozes, 1987.

EVANGELISTA, L.N. A cidade da fumaça: a constituição do grupo operário do bairro do Pequiá no município de Açailândia/MA. 2008. Dissertação (Mestrado em Ciências Sociais) - Universidade Federal do Maranhão, São Luís, 2008.

GREENPEACE. Carvoaria amazônica. Como a indústria de aço e ferro gusa está destruindo a floresta com a participação de governos. Manaus: Greenpeace, 2012. Disponível em: <http://www.greenpeace.org/brasil/pt/Noticias/ Floresta-de-carvao-e-violencia/. Acesso em: 10 jun. 2012.

HARVEY, D. O enigma do capital e as crises do capitalismo. São Paulo: Boitempo, 2011.

HÉBETTTE, J. A luta sindical em resposta às agressões dos grandes projetos. In: _. (Org.). O cerco está se fechando: o impacto do grande capital na Amazônia. Petrópolis; Belém: Vozes; FASE; NAEA, 1991. p. 199-214.

HENDERSON, J. et. al. Redes de Produção Globais e a análise do desenvolvimento econômico. Revista Pós Ciências Sociais, São Luís, n. 15, p. 143-170, 2011.

MATHIEU, L. Rapport au politique, dimensions cognitives et perspectives pragmatiques dans l'analyse des mouvements sociaux. Revue Française de Science Politique, v. 52, n. 1, p. 75-100, 2002.

MONTEIRO, M. de A. A ICOMI no Amapá: meio século de exploração mineral. Novos Cadernos do NAEA, Belém, v. 6, n. 2, p.113-168, 2003.

Em busca de carvão vegetal barato: o deslocamento de siderúrgicas para a Amazônia. Novos Cadernos do NAEA, Belém, v. 9, n. 2, p. 55-97, 2006.

Siderurgia e carvoejamento na Amazônia: drenagem enérgeticomaterial e pauperização regional. Belém: UFPA, 1998.

Novos Cadernos NAEA • v. 16 n. 1 • p. 7-28 • jun. 2013 
NEVEU, É. Sociologie des mouvements sociaux. Paris: Editions de La Decouverte, 2000.

OLIVIER DESARDAN,J.-P.Anthropology and Development-understanding contemporary social change. London; New York: Zed Books, 2005.

PHILLIPS, N. Mirando nas redes globais de produção e acertando no trabalho forçado. In: FIGUEIRA, R.R. et al. (Org.). Trabalho escravo contemporâneo: um debate transdisciplinar. Rio de Janeiro: Mauad X, 2011. p. 157-177.

PITOMBEIRA, K.S. A construção da responsabilidade social empresarial no Polo Siderúrgico de Carajás: o caso do Instituto Carvão Cidadão. 2011. Dissertação (Mestrado em Ciências Sociais) - Universidade Federal do Maranhão, São Luís, 2011.

RAMALHO, J.R. Fórum Demissão Zero - crise e ação coletiva no Sul fluminense. In: RAMALHO, J.R.; FORTES, A. (Org.). Desenvolvimento, trabalho e cidadania: Baixada e Sul Fluminense. Rio de Janeiro: 7 Letras, 2012. p. 225-246.

SANTOS, R.S.P. A forja de Vulcano: siderurgia e desenvolvimento na Amazônia oriental e no Rio de Janeiro. 2010. Tese (Doutorado em Sociologia e Antropologia) - Universidade Federal do Rio de Janeiro, Rio de Janeiro, 2010.

Redes de produção globais (RPGs): contribuições conceituais para a pesquisa em ciências sociais. Revista Pós Ciências Sociais, São Luís, n. 15, p. 127-141, 2011.

SELWYN, B. Beyond firm-centrism: re-integrating labour and capitalism into global commodity chain analysis. Journal of Economic Geography, n. 12, p. 205-226, 2012.

TILLY, C.; TARROW, S. Contentious politics. London, Paradigm Publishers, 2007.

Politique(s) du conflit. De la grève à la révolution. Paris: Les Presses de Sciences Po, 2008.

Matérias de jornais impressos

APÓS acordo, metalúrgicos encerram greve em Açailândia. Jornal dos Metalúrgicos, n. 4, 2011, p. 1-2.

CLAUDIO Azevedo é empossado na Asibras. O Imparcial, 3 jun. 2009, p. 7.

DIA 3 de agosto de 2010 metalúrgicos e deputados discutem crise no polo siderúrgico de Açailândia na Assembleia Legislativa do Maranhão. Jornal dos Metalúrgicos, n. 3, 2010, p. 2. 
SINDICATO dos Metalúrgicos de Açailândia pede apoio ao presidente do Senado José Sarney para Polo Siderúrgico em Açailândia. Jornal dos Metalúrgicos, n. 2, 2010, p. 1.

\section{Matérias de jornais online}

CIDADE do Maranhão registra corte de 40\% dos metalúrgicos, Folha Online, 28.02.2009. Disponível em: <http://www1.folha.uol.com.br/folha/dinheiro/ ult91u510564.shtml>. Acesso em: 20 maio 2012.

VALE: metalúrgicos de Açailândia realizam audiência pública. Portal dos Metalúrgicos do Brasil. 02.09.2010. Disponível em: <http://www.cnmcut.org. br/verCont.asp?id=24781>. Acesso em: 15 maio 2012.

METALÚRGICOS de Açailândia divulgam manifesto contra práticas da Vale. Portal dos Metalúrgicos do Brasil. 12 jul. 2010. Disponível em: <http:/ /www. cnmcut.org.br/verCont.asp?id=23657>. Acesso em: 22 maio 2012.

TRABALHADORES na Viena Siderúrgica entram em greve no Maranhão. Portal dos Metalúrgicos do Brasil. 14 fev. 2011. Disponível em: <http:/ /www. cnmcut.org.br/v_erCont.asp?id=26414>. Acesso em: 15 maio 2012.

BALANÇA Comercial por Unidades da Federação: <http:// www.desenvolvimento.gov.br// sitio/interna/interna.php? area =5\&menu=1078\&refr=1076>. Acesso em: 22 maio 2012.

\section{Documentos}

CARTA do Movimento Popular em Favor da Justiça e da Dignidade Humana. Açailândia, 21.05.2009.

FEDERAÇÃO INTERNACIONAL DOS DIREITOS HUMANOS/JUSTIÇA GLOBAL/JUSTIÇA NOS TRILHOS. Brasil, quanto valem os direitos humanos? Os impactos sobre os direitos humanos relacionados à indústria da mineração e da siderurgia em Açailândia, 2011, 563 p.

\section{Entrevistas}

IPOJUCAM, Ítalo. Associação Comercial Industrial de Marabá (ACIM). Entrevista concedida. Marabá, 22 jan. 2009.

JARLIS, Adelino; DIRETORIA do Sindicato dos Metalúrgicos de Açailândia. Entrevista concedida. Açailândia, 16 fev. 2012. 